\title{
Avaliação de linhagens promissoras de feijoeiro (Phaseolus vulgaris L.) tolerantes ao déficit hídrico
}

\section{Evaluation of hydric deficit -tolerant promising bean (Phaseolus vulgaris 1.) lines}

\author{
Ricardo Sfeir de Aguiar ${ }^{1}$; Vania Moda-Cirino ${ }^{2 *}$; Rogério Teixeira Faria ${ }^{3}$; \\ Luiz Henrique Ilkiu Vidal ${ }^{4}$
}

Resumo

O objetivo deste estudo foi avaliar a reação ao déficit hídrico de cinco genótipos de feijoeiro do grupo comercial preto e cinco do grupo comercial carioca. Foram estabelecidos em Londrina (PR), na safra das águas 2002/2003, dois experimentos independentes, um para cada grupo. O déficit hídrico foi imposto durante vinte dias na fase de início de florescimento, por meio de abrigos móveis de ferro, cobertos com telhas transparentes, para proteger da chuva. Durante o período de déficit hídrico, foi determinada a umidade do solo em ambos os tratamentos (com e sem déficit). No estádio de maturação físiológica, foram amostradas, ao acaso, 10 plantas de cada subparcela, avaliando-se número de nós, altura da planta, número de vagens por planta, número de sementes por vagem, peso médio de 100 sementes, rendimento por planta e rendimento total. As estimativas dos coeficientes de variação genética, coeficiente de determinação genotípica e índice B indicaram alta variabilidade genética entre os genótipos. As estimativas dos coeficientes de correlação fenotípica revelaram a presença de caracteres correlacionados, indicando a possibilidade de se efetuar a seleção simultânea entre eles. Com base no índice de redução de produtividade e no rendimento total de grãos sem estresse ( $\mathrm{kg} / \mathrm{ha})$, a linhagem LP 99-85 do grupo preto e a linhagem LP 99-79 do grupo carioca destacaram-se como as mais tolerantes ao déficit hídrico. A linhagem LP99-79 esta sendo registrada para cultivo no SNRC/ MAPA com a denominação de IPR Siriri.

Palavras-chave: Estresse hídrico, melhoramento genético, cultivares

\begin{abstract}
The aim of this study was to evaluate the reaction to hydric deficit of five bean genotypes of the black commercial group and five bean genotypes of the Carioca commercial group. Two experiments had been carried out in Londrina (PR) in 2002/2003 wet season. The hydric deficit was obtained during twenty days in the beginning of blooming phase. Mobile shelters constructed in iron had been used and covered with transparent roofing tiles to prevent the rain. During the period of hydric deficit, the soil humidity was determined in both treatments. In the phase of physiological maturation 10 plants of each subparcel were evaluated for number of knot, plant height, number of pods per plant, number of seeds per pod, 100 seed weight, plant yield and total yield. The estimates of the coefficients of genetic variation, coefficient of genotypic determination and B index indicated high genetic variability between the genotypes. The estimates of the coefficients of phenotypic correlation showed the presence of correlated characters indicating the possibility of doing simultaneous election between them. Based on the index of yield reduction and on the total yield of grains without hydric stress ( $\mathrm{kg} / \mathrm{ha}$ ) genotype LP 99-85 of the black group and genotype LP 99-79 of the Carioca group were identified as tolerant to hydric deficit. The line LP99-79 has been registered for cultivation in the SNRC / MAP with the designation of IPR Siriri.

Key words: Hydric stress, genetic improvement, cultivates
\end{abstract}

\footnotetext{
1 Eng ${ }^{\circ}$ Agr ${ }^{\circ}$. Mestre em agronomia, Universidade Estadual de Londrina, PR. E-mail: rsaguiar@hotmail.com

2 Pesquisadora da Área de Melhoramento e Genética Vegetal, IAPAR, Londrina-PR. E-mail: vamoci@iapar.br

3 Pesquisador da Área de Engenharia Agrícola, IAPAR, Londrina-PR.

4 Eng $^{\mathrm{o}} \mathrm{Agr}^{\mathrm{o}}$. Mestre em agronomia, Universidade Estadual de Londrina, PR.

* Autor para correspondência
} 


\section{Introdução}

O Brasil é um dos principais produtores mundiais de feijão, cultivando anualmente 4.087 .400 ha com uma produção em torno de 3.338.700 toneladas (COMPANHIA NACIONAL DE ABASTECIMENTO - CONAB, 2007). O Paraná é o principal estado produtor, sendo responsável por aproximadamente $23 \%$ da produção nacional, com uma área cultivada de 563.300 ha e uma produção de 795.300 toneladas (COMPANHIA NACIONAL DE ABASTECIMENTO - CONAB, 2007).

Embora o feijoeiro seja cultivado em quase todo o Estado do Paraná, a produção concentra-se em algumas regiões, predominando o cultivo do feijão de cores na região Norte e do feijão preto na região Sul, atendendo às exigências do mercado consumidor. A participação das pequenas propriedades na produção é expressiva, sendo os estabelecimentos rurais com menos de 50 ha, responsáveis por aproximadamente $80 \%$ da produção.

Tradicionalmente, o feijão é cultivado em três épocas, a das águas, a da seca e a de outono-inverno. $\mathrm{O}$ cultivo de outono-inverno concentra-se na região Norte do Estado e constitui uma atividade de alto risco, devido à alta probabilidade de ocorrência de déficit hídrico (veranicos) durante o desenvolvimento da cultura.

O feijoeiro é considerado uma espécie com pouca tolerância a estresses hídricos severos, sendo que $60 \%$ da produção mundial está submetida a este fator, tornando a seca o segundo maior redutor da produtividade, a qual é superada apenas pela ocorrência de doenças. Em virtude de apresentar um ciclo de aproximadamente 90 dias, a necessidade de água do feijoeiro está além das espécies geralmente consideradas mais adaptadas ao estresse hídrico (WHITE, 1993). Algumas práticas de manejo podem contribuir para o aumento da produtividade em condições de estresse hídrico, entretanto, o maior progresso tem sido obtido através do melhoramento genético (WHITE et al., 1994; SINGH, 1995).

Em estudos de avaliação de cultivares para resistência à seca, verificou-se que a produção de grãos diminui à medida que o número de dias de estresse aumenta (SILVEIRA et al.,1981). Independente da magnitude do estresse hídrico, genótipos de feijoeiro respondem de maneira diferenciada ao déficit de água no solo durante o período da floração (KARAMANOS; PAPATHEOHARI, 1999; SINGH, 1995; SCHNEIDER; BROTHERS; KELLY, 1997; MOLINA et al., 2001).

A redução na produção do feijoeiro sob estresse hídrico é decorrente da baixa porcentagem de vingamento das flores, quando ocorre durante a floração, e ao,abortamento de óvulos produzindo vagens chochas, quando ocorre na formação das mesmas (PARJER, 1976; GARRIDO; PURCINO; LIMA, 1979; RAMIREZ-VALLEJO; KELLY, 1998), o que ocasiona um decréscimo na produção de $42 \%$ e $50 \%$ respectivamente. O número de dias em que o feijoeiro fica sujeito à redução de água no solo, durante os períodos críticos também influencia na redução da produtividade, proporcionando decréscimos de até $20 \%$ no rendimento (MAGALHÃES; MILLAR, 1978).

Como conseqüência, têm-se encontrado uma alta correlação positiva entre disponibilidade de água no solo e alguns componentes do rendimento. Blum (1997), recomenda o uso de parâmetros correlacionados com o rendimento da cultura, e de fácil mensuração, ao invés de avaliações como a acumulação de proteínas. Em decorrência de o rendimento ser a característica econômica mais importante, as avaliações de performance de genótipos tolerantes à seca, são efetuadas mensurando-se as características a ele relacionadas (ACOSTA-GALLWGOS; ADAMS, 1991).

No presente estudo avaliou-se a reação ao déficit hídrico de sete linhagens promissoras de feijoeiro provenientes do programa de melhoramento do Instituto Agronômico do Paraná - IAPAR, e de uma cultivar obtida no Instituto Agronômico de Campinas (IAC). Visando obter variedades superiores, foram, selecionadas as mais tolerantes, para serem 
futuramente registradas para cultivo no estado do Paraná, ou serem utilizadas como parentais no melhoramento genético.

\section{Material e Métodos}

A reação ao déficit hídrico de oito genótipos de feijoeiro, foi avaliada em dois experimentos independentes, um para cada grupo comercial, preto e carioca As linhagens avaliadas foram: LP 99-80, LP 99-85, LP 99-96 e LP 99-81 (grupo preto) e LP9979, LP 99-55, LP 99-63 e a cultivar IAC Carioca Tybatã (grupo carioca). As cultivares IPR Uirapuru e IAPAR 81, respectivamente dos grupos preto e carioca, classificadas como moderadamente tolerante ao déficit hídricos (MODA-CIRINO et al., 2001a, 2001b; MOLINA et al., 2001), foram utilizadas como testemunhas para resistência à seca..

Os experimentos foram conduzidos na Estação Experimental do Instituto Agronômico do Paraná (IAPAR), em Londrina-PR, no ano agrícola 2002/ 2003, na safra das águas, em situações com e sem estresse hídrico. As semeaduras ocorreram na segunda quinzena de agosto para o grupo comercial carioca e na primeira quinzena de setembro para o grupo comercial preto.

Os ensaios foram estabelecidos em três canteiros com laterais de concreto e dimensões de $100 \mathrm{~m}$ de comprimento por $5 \mathrm{~m}$ de largura e $1,0 \mathrm{~m}$ de profundidade. $\mathrm{O}$ solo da área é classificado como Latossolo Roxo Distrófico, cujas características físico-líticas foram descritas por Faria e Madramootoo (1996).

O delineamento experimental utilizado foi o de blocos ao acaso, com três repetições e parcelas subdivididas. Os tratamentos com e sem estresse hídrico constituíram as parcelas e os genótipos, as subparcelas. As subparcelas foram compostas por quatro linhas de $5 \mathrm{~m}$, espaçadas a $0,5 \mathrm{~m}$, com densidade de semeadura de 20 sementes viáveis por metro linear. Após a emergência foi efetuado o desbaste, deixando-se 15 plantas por metro linear.
A adubação de base foi realizada no dia da semeadura, de acordo com análise química do solo. Aos 22 dias após a emergência foi realizada uma adubação nitrogenada em cobertura, aplicando-se 200 $\mathrm{kg} / \mathrm{ha}$ de sulfato de amônia.

A ocorrência de plantas invasoras, pragas e doenças foi controlada com a utilização de produtos químicos, com exceção do crestamento bacteriano comum, uma vez que não existe controle químico eficiente para esta doença.

Todas as parcelas foram irrigadas por aspersão até o início do estádio de desenvolvimento R6 (florescimento); cessando a irrigação, por 20 dias nas parcelas submetidas ao estresse hídrico. Para evitar a incidência de chuvas nestas parcelas, foram utilizados abrigos móveis com sistema de roldanas, deslizantes sobre trilhos de ferro, acoplados às laterais dos canteiros. Os abrigos foram construídos em ferro, com coberturas e laterais de polietileno transparente, com dimensões de $10 \mathrm{~m}$ de comprimento por $5 \mathrm{~m}$ de largura e 2,8 $\mathrm{m}$ de altura.

Durante o período de estresse hídrico foi determinada a umidade do solo, utilizando-se o método gravimétrico, para a profundidade de $0-10 \mathrm{~cm}$ e sonda de nêutrons, para as profundidades de $10-25 \mathrm{~cm}$ e 25-40 cm. As determinações foram realizadas nos tratamentos com e sem estresse hídrico, em uma freqüência de duas vezes por semana. A partir desses dados, foi calculado o armazenamento de água no solo no perfil de 0-70 cm (FARIA; MADRAMOOTOO, 1996).

No estádio de maturação fisiológica R9 foram amostradas dez plantas, ao acaso, da área útil de cada subparcela, e avaliados os seguintes caracteres:

NN: número de nós no caule principal; AP: altura da planta (comprimento do caule principal em $\mathrm{cm}$ ); VP: número de vagens por planta; SV: número de sementes por vagem; PMS: peso médio de 100 sementes (g); RP: rendimento por planta (g); RT: rendimento total $(\mathrm{kg} / \mathrm{ha})$. 
Com a finalidade de estimar o efeito do estresse hídrico sobre o crescimento da planta, foram determinados alguns parâmetros de crescimento, tais como, índice de área foliar (IAF) e taxa de matéria seca (TMS), obtidos através das seguintes expressões:

Índice de área foliar: $\mathrm{IAF}=\mathrm{AF}\left(\mathrm{m}^{2}\right) \times \mathrm{N}$ (ha); onde, $\mathrm{AF}$ - área foliar de uma planta; N- número de plantas/ hectare.

Área foliar (AF): $\mathrm{AF}=\mathrm{NF} \times \mathrm{F} \times \mathrm{L} \times \mathrm{C}$; onde,

NF- número total de folhas da planta; F- fator de correção; L- largura da folha em metro; Ccomprimento da folha em metro.

Taxa de matéria seca: $\mathrm{TMS}=\mathrm{N} \times \mathrm{P}$; onde,

$\mathrm{N}$ - número de plantas/hectare; P- peso seco de uma planta.

Para realização do IAF e da TMS, foram selecionadas uma linhagem do grupo preto (LP 9996), uma do grupo carioca (LP 99-63) e suas respectivas testemunhas.

Para cálculo do IAF foram selecionadas, ao acaso dez folhas e efetuadas as mensurações de largura e comprimento de cada folha, tendo sido contado também o número total de folhas de três plantas de cada repetição (com e sem estresse hídrico) referente aos genótipos mencionados acima. Isto ocorreu aos 35, 60 e 75 dias após a emergência da planta.

Para o cálculo do TMS foram selecionadas quatro plantas de cada repetição (com e sem estresse hídrico) referentes aos genótipos mencionados acima. Estas foram colocadas em estufas à $90^{\circ} \mathrm{C}$ durante três dias e após isso foram retiradas e pesadas. Esta seleção também ocorreu aos 35, 60 e 75 dias após a emergência da planta.

A análise estatística dos dados obtidos foi efetuada utilizando-se do programa GENES (CRUZ, 1997) considerando-se os efeitos de tratamentos e genótipos como fixos.
A análise de variância foi realizada segundo o modelo estatístico:

$$
\mathrm{Y}_{\mathrm{ijk}}=\mu+\mathrm{b}_{\mathrm{k}}+\mathrm{p}_{\mathrm{i}}+\varepsilon_{\mathrm{ik}}+\mathrm{s}_{\mathrm{j}}+\mathrm{ps}_{\mathrm{ij}}+\delta_{\mathrm{ijk}}
$$

$\mathrm{Y}_{\mathrm{ijk}}$ : valor observado na parcela $\mathrm{i}$, na subparcela $\mathrm{j}$, na repetição $\mathrm{k} ; \mu$ : média geral do ensaio;

$\mathrm{b}_{\mathrm{k}}$ : repetição $\mathrm{k} ; \mathrm{p}_{\mathrm{i}}$ :parcela $\mathrm{i}$;

$\varepsilon_{\mathrm{ik}}$ : erro a; $\mathrm{s}_{\mathrm{j}}$ : subparcela $\mathrm{j}$;

$\mathrm{ps}_{\mathrm{ij}}$ : interação parcela x subparcela;

$\delta_{\mathrm{ijk}:}$ erro b.

O programa GENES (CRUZ, 1997) fornece todas as matrizes de correlações fenotípicas. A significância destas correlações foi testada pelo teste $\mathrm{T}$ com n-2 graus de liberdade a $5 \%$ e $1 \%$ de probabilidade (STELL; TORRIE, 1960).

Para todas as características avaliadas nos genótipos, foi obtido um índice de redução (IR\%), por meio da expressão:

Sem estresse - com estresse x 100 / Sem estresse

\section{Resultados e Discussão}

As Figuras 1 e 2 mostram, respectivamente, para os grupos comerciais preto e carioca, o armazenamento de água no solo na camada de 0 $70 \mathrm{~cm}$, durante o período de estresse hídrico. Em ambos os grupos, pode-se comprovar a ocorrência do déficit hídrico no tratamento com estresse, e a não ocorrência deste, no tratamento sem estresse. O armazenamento de água no solo variou, aproximadamente, de $175 \mathrm{~mm}$ a $215 \mathrm{~mm}$ para o tratamento com estresse, em ambos os grupos, sendo o ponto de murcha permanente situado abaixo de $196 \mathrm{~mm}$ de água no perfil deste solo. No tratamento sem estresse, a maior parte dos pontos da curva 
situou-se acima de 50\% de água disponível no solo, chegando próximo ou até superando a capacidade de campo, calculada em $251 \mathrm{~mm}$ de água para este perfil, neste solo. Segundo Acosta-Gallegos (1988), a cultura do feijoeiro não tem sua produção afetada quando a água disponível no solo é mantida acima de $50 \%$ da água disponível.

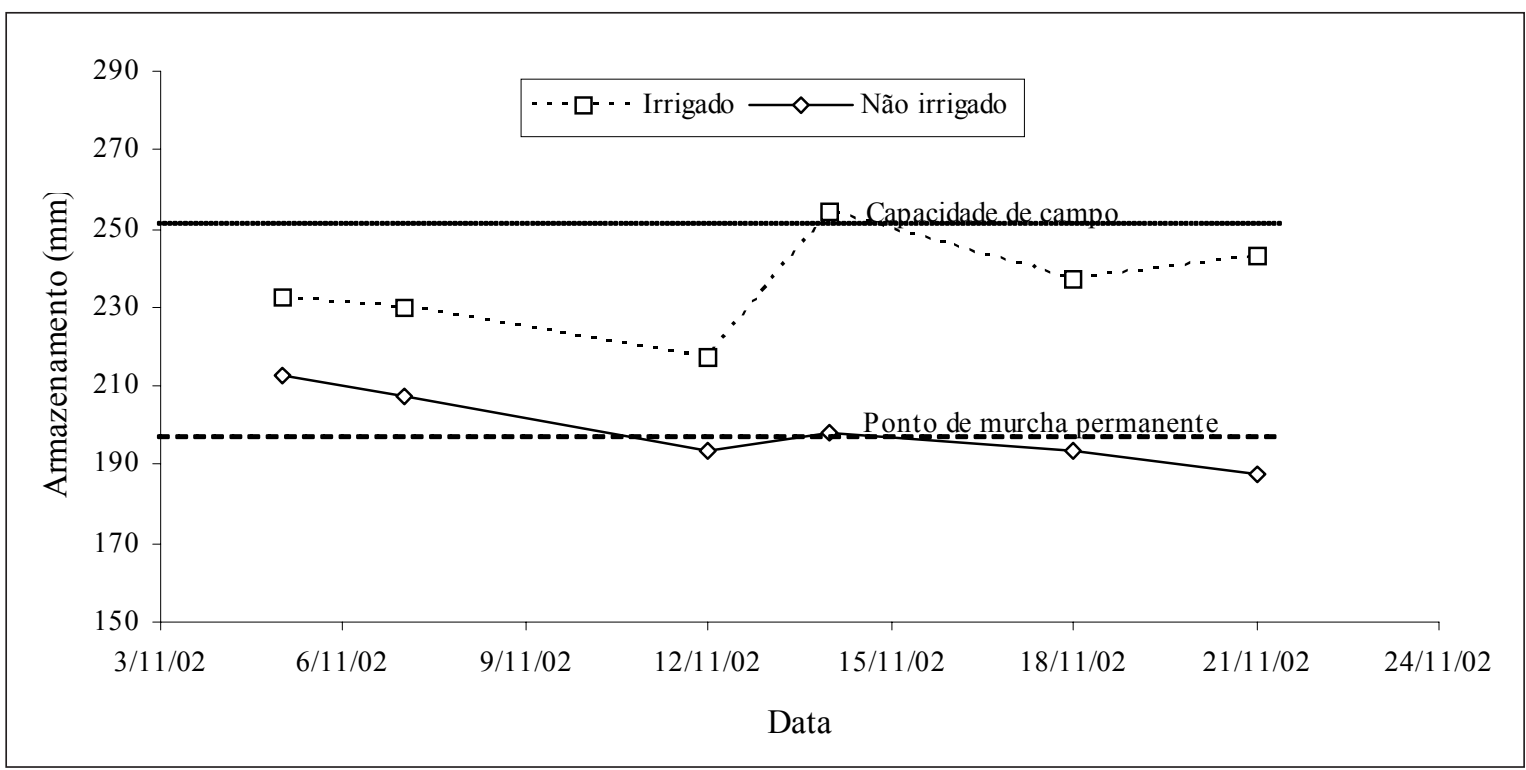

Figura 1. Armazenamento de água de $0-70 \mathrm{~cm}$ no perfil de Latossolo Roxo distrófico, para genótipos de feijoeiro pertencentes ao grupo preto, com e sem estresse hídrico. Londrina-PR, safra das águas 2002/2003

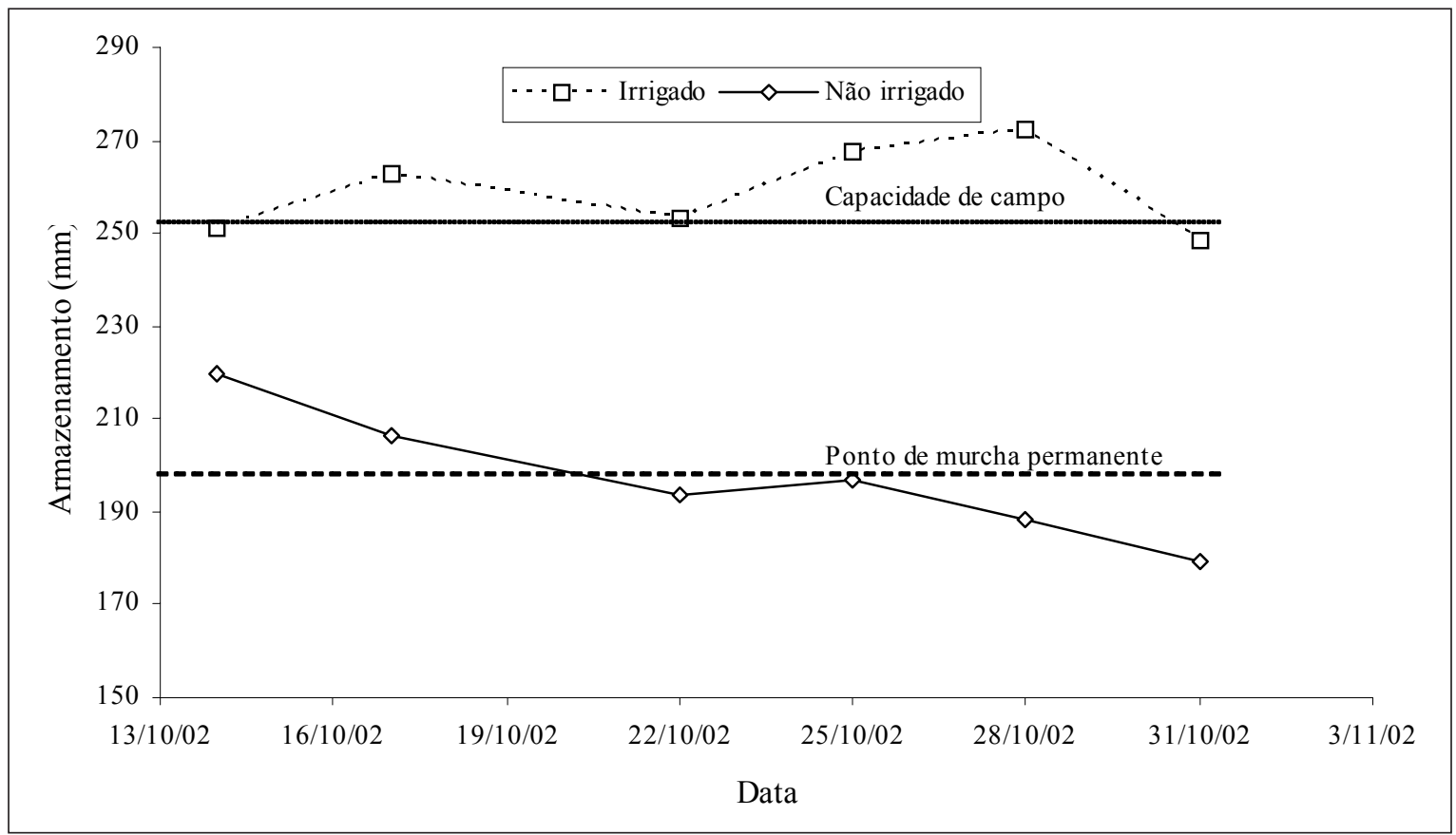

Figura 2. Armazenamento de água de $0-70 \mathrm{~cm}$ no perfil de Latossolo Roxo distrófico, para genótipos de feijoeiro pertencentes ao grupo carioca, com e sem estresse hídrico. Londrina-PR, safra das águas 2002/2003 
Na Tabela 1 encontra-se um resumo da análise de variância para os sete caracteres estudados nos dois grupos de feijão, preto e carioca. Dentro do grupo comercial preto os efeitos de tratamentos foram significativos a $1 \%$ de probabilidade para os caracteres número de vagem por planta, rendimento por planta e rendimento total; e não significativos para os demais caracteres; os efeitos de genótipos foram significativos à $1 \%$ de probabilidade somente para peso de 100 sementes e rendimento total, já dentro do grupo carioca, a análise da Tabela 1 permite verificar que os efeitos de genótipos apresentaram significância a 5\% de probabilidade para o caracter rendimento por planta; a $1 \%$ de probabilidade para os caracteres altura da planta, peso de 100 sementes e rendimento total; e não significativos para as demais características; para os efeitos de tratamentos, para o grupo carioca foram significativos a $1 \%$ de probabilidade somente os caracteres altura de planta, número de vagem por planta, rendimento por planta e rendimento total.

Tabela 1. Resumo das análises de variância, coeficientes de variação genética $(\mathrm{CVg} \%)$, coeficientes de variação ambiental (Cve\%) e índice B (\%), de sete características pertencentes ao grupo comercial preto e ao grupo comercial carioca, com e sem estresse hídrico, Londrina-PR, safra das águas 2002/2003.

\begin{tabular}{lccccccc}
\hline \multicolumn{7}{c}{} & \multicolumn{7}{c}{ Grupo comercial preto } \\
\hline FV & AP & NN & VP & SV & PMS & RP & RT \\
\hline Tratamentos & ns & ns & $* *$ & ns & ns & $* *$ & $* *$ \\
Genótipos & ns & ns & ns & ns & $* *$ & ns & $* *$ \\
Interação & ns & ns & ns & ns & ns & ns & ns \\
\hline CVg\% & 4,6 & 2,6 & 7,4 & 4,8 & 6,5 & 10,0 & 13,0 \\
Cve\% & 8,0 & 5,9 & 21,2 & 9,6 & 5,3 & 17,5 & 13,0 \\
B\% & 57,5 & 44,1 & 34,9 & 50,0 & 122,6 & 57,1 & 100,0 \\
\hline & & & & Grupo comercial carioca & \\
\hline Tratamentos & $* *$ & $\mathrm{~ns}$ & $* *$ & $\mathrm{~ns}$ & $\mathrm{~ns}$ & $* *$ & $* *$ \\
Genótipos & $* *$ & $\mathrm{~ns}$ & $\mathrm{~ns}$ & $\mathrm{~ns}$ & $* *$ & $*$ & $* *$ \\
Interação & $*$ & $\mathrm{~ns}$ & $* *$ & $\mathrm{~ns}$ & $\mathrm{~ns}$ & $\mathrm{~ns}$ & $\mathrm{~ns}$ \\
\hline CVg\% & 8,1 & 1,5 & 8,1 & 3,7 & 7,8 & 16,4 & 44,4 \\
Cve\% & 7,7 & 4,0 & 15,4 & 10,2 & 7,1 & 22,7 & 21,8 \\
B\% & 105,2 & 37,5 & 52,6 & 36,3 & 109,9 & 72,2 & 203,6 \\
\hline
\end{tabular}

ns: não significativo; **: significativo a $1 \%$ de probabilidade; $*$ : significativo a 5\% de probabilidade;

AP: altura da planta; NN:número de nós no caule principal; VP: número de vagem por planta; SV: número de semente por vagem; PMS: peso médio de 100 sementes (g); RP: rendimento por planta (g); RT: rendimento total (kg/ha)

A interação tratamentos $\mathrm{x}$ genótipos apresentou significância somente para o grupo carioca à $1 \%$ de probabilidade para o caracter número de vagem por planta e a $5 \%$ de probabilidade para a característica altura de planta. Para o grupo preto não houve interação significativa para nenhum dos caracteres avaliados, o que indica uma redução de igual intensidade em condições de estresse para essas características.

Nas estimativas dos coeficientes de variação genética $(\mathrm{CVg} \%)$ e dos coeficientes de variação ambiental ( $\mathrm{CVe} \%)$, bem como o índice B (B\%) dos caracteres avaliados nos genótipos pertencentes aos grupos preto e carioca (Tabela 1), observa-se que 
para o grupo comercial preto o maior coeficiente de variação genética ocorreu para o caráter rendimento total $(13 \%)$ e o menor (2,6\%), para número de nós por planta. O coeficiente de variação ambiental do experimento, variou de 5,3\% para peso de 100 sementes a $21,2 \%$ para número de vagem por planta. $\mathrm{O}$ índice $\mathrm{B}$, o qual fornece uma indicação da variabilidade genética de um caráter sem influência da média geral do mesmo, variou de $44,1 \%$, para número de nós por planta a $122,6 \%$ para peso de 100 sementes.

Para o grupo comercial carioca o caracter que apresentou a maior estimativa de coeficiente de variação genética foi o rendimento total $44,4 \%$ e o menor $1,5 \%$ para número de nós por planta. $\mathrm{O}$ coeficiente de variação ambiental do experimento variou de $4,0 \%$ para número de nós por planta a $22,7 \%$ para rendimento por planta. Os maiores índices B ocorreram para peso de 100 sementes $(109,9 \%)$ e rendimento total (206,66\%). Valores de B acima de $100 \%$ indicam uma situação muito favorável à seleção, sendo o efeito de genótipos muito significativo. Quando o efeito de genótipos não é significativo, espera-se índice B baixo, $\mathrm{CVg}$ baixo e CVe alto.

As estimativas dos $\mathrm{CVg} \%, \mathrm{CVe} \%$ e B indicaram a presença de alta variabilidade genética entre os genótipos estudados, destacando-se as características peso de 100 sementes e rendimento total para o grupo preto e altura de planta, peso de 100 sementes e rendimento total para o grupo carioca

Os resultados obtidos mostram que a supressão hídrica, ocorrida durante as fases de florescimento e início de desenvolvimento das vagens, ocasionou redução na maioria das características avaliadas, evidenciando a suscetibilidade de genótipos de feijoeiro ao estresse hídrico, neste estádio de desenvolvimento(Tabela 2). Resultados semelhantes foram obtidos por Dubetz e Mahille (1969), Raggi, Bernardo e Galvão (1972), Oliveira e Faria (1996), Nielsen e Nelson (1998), Ramirez-Vallejo e Kelly (1998), Pimentel; Laffray e Louguet (1999) e Molina et al. (2001).
Analisando a Tabela 2, observa-se que os genótipos do grupo comercial preto, quando submetidos ao estresse hídrico, apresentaram uma redução para altura de planta variando de $4,6 \%$ a $17,3 \%$. Para o grupo carioca, todos os genótipos avaliados apresentaram um aumento na altura da planta em condições de estresse. Tal resultado pode ser conseqüência do estiolamento das plantas quando submetidas a essas condições. Para a característica número de nós, observa-se uma pequena redução em todos os genótipos, sendo que para o grupo preto variou de $0,0 \%$ a $8,7 \%$, e no grupo carioca apenas a linhagem LP 99-79 apresentou um pequeno aumento no número de nós $(-2,4 \%)$, sendo que para as demais a redução também foi pequena variando de $1,8 \%$ a $5,3 \%$.

Quanto ao número de vagens por planta, houve redução desta característica em ambos os grupos, variando de $50,4 \%$ a $69,1 \%$ para o grupo preto e de $11,1 \%$ a $58,5 \%$ para o grupo carioca. Para número de sementes por vagem, os genótipos IAPAR 81, IAC Carioca Tybatã e LP 99-55 do grupo carioca, apresentaram um aumento, em condições de estresse, variando de $-1,6 \%$ a $-10,0 \%$, já para o grupo preto todos os genótipos sofreram uma redução que variou de $0,4 \%$ a $31 \%$ pra esta característica. Este resultado indica que o déficit hídrico imposto não causou abortamento dos embriões, e sim, influenciou no enchimento dos grãos, que ficaram chochos. Isto pode ser constatado analisando a Tabela 2 , onde verifica a ocorrência de drásticas reduções no rendimento por planta, em condições de estresse para ambos os grupos.

Para a característica peso médio de 100 sementes pode-se observar, dentro do grupo preto, que houve uma redução variando de $-8,5 \%$ para a cultivar IPR Uirapuru a 3,4\% para a linhagem LP 99-96, já para o grupo comercial carioca a linhagem LP 99-79 apresentou a menor redução $(-20,1 \%)$ e a cultivar IAPAR 81 foi a que apresentou o maior índice de redução $(12,1 \%)$. 
Tabela 2. Índices de redução em porcentagem, dos caracteres avaliados em genótipos de feijoeiro pertencentes ao grupo comercial preto, e grupo comercial carioca, com e sem estresse hídrico. Londrina-PR, safra das águas 2002/2003

\begin{tabular}{lccccccc}
\hline & \multicolumn{7}{c}{ Grupo comercial preto } \\
\hline genótipos & AP & NN & VP & SV & PMS & RP & RT \\
LP 99-85 & 4,6 & 0,0 & 50,4 & 10,9 & 3,1 & 52,5 & 62,0 \\
\hline LP 99-80 & 6,8 & 3,8 & 51,3 & 16,1 & 2,0 & 63,6 & 62,0 \\
LP 99-96 & 5,5 & 5,2 & 69,1 & 0,4 & 3,4 & 67,4 & 71,0 \\
LP99-81 & 11,5 & 4,4 & 52,7 & 6,9 & $-7,2$ & 69,1 & 74,0 \\
IPR Uirapuru & 17,3 & 8,7 & 53,4 & 31,0 & $-8,5$ & 68,5 & 70,5 \\
\hline & & \multicolumn{7}{c}{ Grupo comercial carioca } \\
\hline genótipos & AP & NN & VP & SV & PMS & RP & RT \\
LP 99-79 & $-33,7$ & $-2,4$ & 11,1 & 12,4 & $-20,1$ & 36,8 & 36,0 \\
LP 99-63 & $-3,7$ & 5,3 & 58,3 & 13,4 & $-3,8$ & 62,8 & 50,0 \\
LP 99-55 & $-22,3$ & 1,8 & 53,1 & $-10,0$ & $-1,6$ & 54,7 & 45,0 \\
IAC Tybatã & $-2,3$ & 4,5 & 58,5 & $-1,6$ & 7,2 & 51,9 & 39,0 \\
IAPAR 81 & $-4,2$ & 3,0 & 56,3 & $-7,1$ & 12,1 & 39,6 & 31,0 \\
\hline
\end{tabular}

AP: altura da planta; NN:número de nós no caule principal; VP: número de vagem por planta; SV: número de semente por vagem; PMS: peso médio de 100 sementes (g); RP: rendimento por planta (g); RT: rendimento total ( $\mathrm{kg} / \mathrm{ha})$

O rendimento total de grãos $(\mathrm{kg} / \mathrm{ha})$ é a característica economicamente mais importante e, por conseqüência, a que mais reflete os efeitos do déficit hídrico. Observa-se que as linhagens LP 9985 e LP 99-80 do grupo preto apresentaram o menor índice de redução (62\%), e no grupo carioca a variedade IAPAR 81 e a linhagem LP 99-79 destacaram-se por também apresentarem o menor índice de redução $31 \%$ e $36 \%$ respectivamente. O comportamento apresentado pela cultivar IAPAR 81, confirma os resultados obtidos por Moda-Cirino et al., (2001a).

Os resultados das estimativas das correlações fenotípicas para os caracteres avaliados nos genótipos pertencentes aos grupos preto e carioca (Tabela 3), evidenciaram que, dentro do grupo preto o rendimento total correlacionou-se positivamente com número de semente por vagem $\left(0,6541^{*}\right)$ e com o rendimento por planta $\left(0,921^{* *}\right)$; número de nós apresentou correlação positiva e estatisticamente significativa com altura de planta $\left(0,7623^{* *}\right)$ e com número de vagem por planta $\left(0,7087^{*}\right)$. O número de vagem por planta correlacionou-se com rendimento por planta $\left(0,6795^{*}\right)$. As correlações negativas não foram estatisticamente significativas.

Correlações negativas e significativas indicam que a seleção de um caracter diminui a expressão do outro (MOLINA et al., 2001). Dentro do grupo carioca, apresentaram correlações negativas número de nós com semente por vagem $\left(-0,926^{* *}\right)$, número de nós com rendimento por planta $\left(-0,993^{* *}\right)$, número de nós com rendimento total $\left(-0,6658^{*}\right)$; e também apresentou correlação negativa e significativa altura de planta com rendimento por planta $\left(-0,6982^{*}\right)$ as demais correlações negativas não apresentaram significância estatística. 
Tabela 3. Estimativas das correlações fenotípicas para os caracteres avaliados em cinco genótipos de feijoeiro do grupo comercial preto (diagonal superior) e em cinco genótipos de feijoeiro do grupo comercial carioca (diagonal inferior), com e sem estresse hídrico. Londrina-PR, safra das águas2002/2003.

\begin{tabular}{cccccccc}
\hline Caracter & AP & NN & VP & SV & PMS & RP & RT \\
\hline AP & & $0,7623^{* *}$ & 0,2283 & 0,1729 & $-0,2547$ & 0,101 & 0,1676 \\
NN & $0,6397^{*}$ & & $0,7087^{*}$ & $-0,1835$ & 0,0435 & 0,3391 & 0,1458 \\
VP & $-0,0336$ & $-0,2438$ & & $-0,377$ & $-0,1383$ & $0,6795^{*}$ & 0,3805 \\
SV & $-0,4515$ & $-0,926^{* *}$ & $-0,0364$ & & 0,2215 & 0,3678 & $0,6541^{*}$ \\
PMS & 0,491 & 0,077 & 0,2406 & $-0,1151$ & & $-0,0151$ & $-0,1142$ \\
RP & $-0,6982^{*}$ & $-0,933^{* *}$ & 0,2316 & $0,914^{* *}$ & $-0,1856$ & & $0,921^{* *}$ \\
RT & $-0,2393$ & $-0,6658$ & $-0,474$ & $0,877^{* *}$ & $-0,0419$ & $0,6406^{*}$ & \\
\hline
\end{tabular}

**: significativo a $1 \%$ de probabilidade; * significativo a $5 \%$ de probabilidade;

AP: altura da planta; NN:número de nós no caule principal; VP: número de vagem por planta; SV: número de semente por vagem; PMS: peso médio de 100 sementes (g); RP: rendimento por planta (g); RT: rendimento total (kg/ha)

A estimativa entre rendimento por planta e semente por vagem, rendimento por planta e rendimento total, semente por vagem e rendimento total, altura de planta e número de nós foram positivas e significativas, apresentando magnitudes de $0,9145^{* *}$, $0,6406^{*} ; 0,8776^{* *} ; 0,6397^{*}$ respectivamente. O conhecimento das correlações existentes entre os caracteres possibilita avaliar a associação entre eles, permitindo ao melhorista conhecer as mudanças que ocorreram em uma determinada característica, em função da seleção praticada em outro caráter que é correlacionado com ele.
As taxas de matéria seca para ambos os grupos preto e carioca (Figuras 3 e 4 respectivamente), apresentam uma drástica redução quando os mesmos foram submetidos ao estresse hídrico e a maior taxa de matéria seca ocorreu por volta dos 60 dias para todos os genótipos avaliados.

Os índices de área foliar para o grupo preto e para o grupo carioca (Figuras 5 e 6 respectivamente) apresentaram uma sensível redução quando os genótipos foram submetidos ao estresse hídrico, e o maior índice de área foliar foi constatada por volta dos 60 dias após a emergência. 


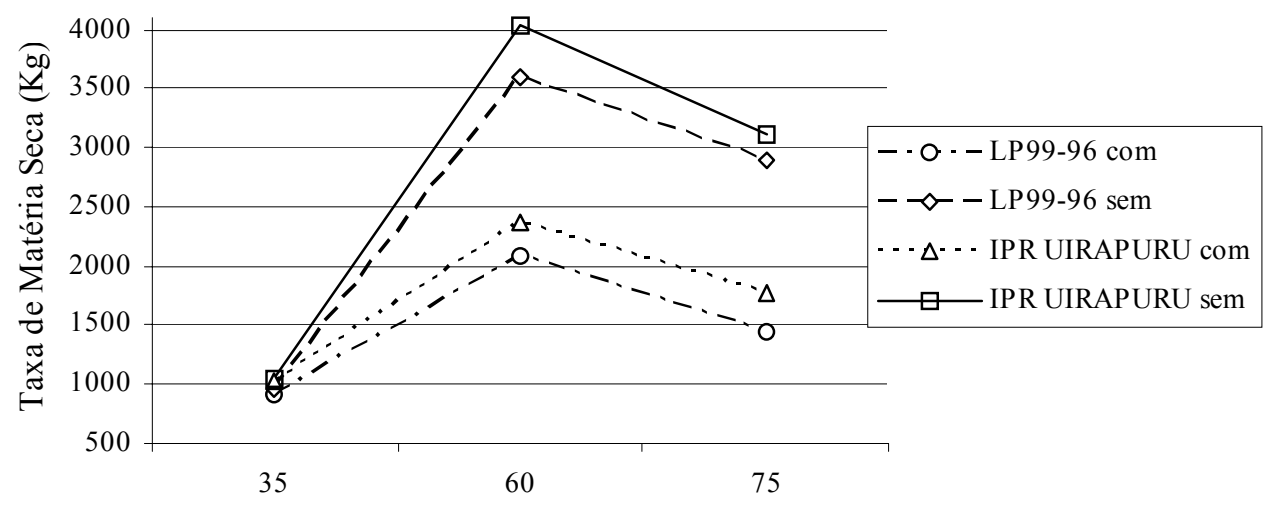

Dias após a Emergência

Figura 3. Taxa de matéria seca em kg, de dois genótipos de feijoeiro pertencentes ao grupo preto, com e sem estresse hídrico. Londrina-PR, safra das águas 2002/2003.

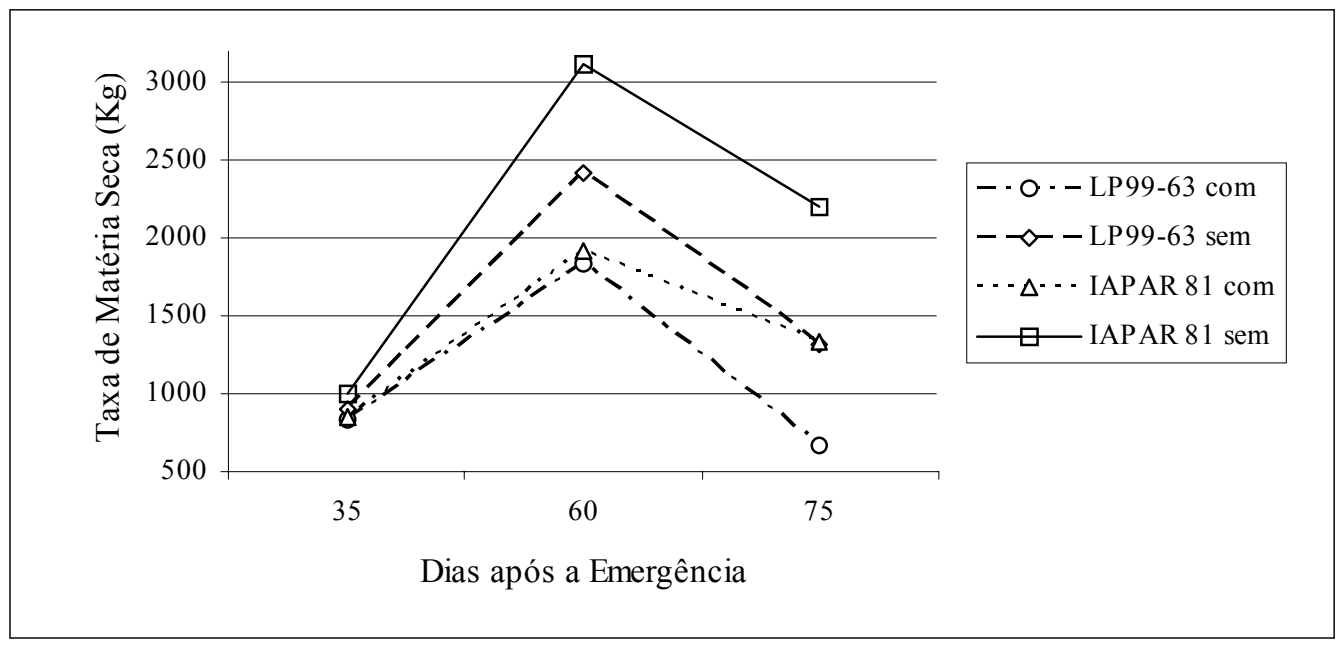

Figura 4. Taxa de matéria seca em $\mathrm{kg}$, de dois genótipos de feijoeiro pertencentes ao grupo carioca, com e sem estresse hídrico. Londrina-PR, safra das águas 2002/2003.

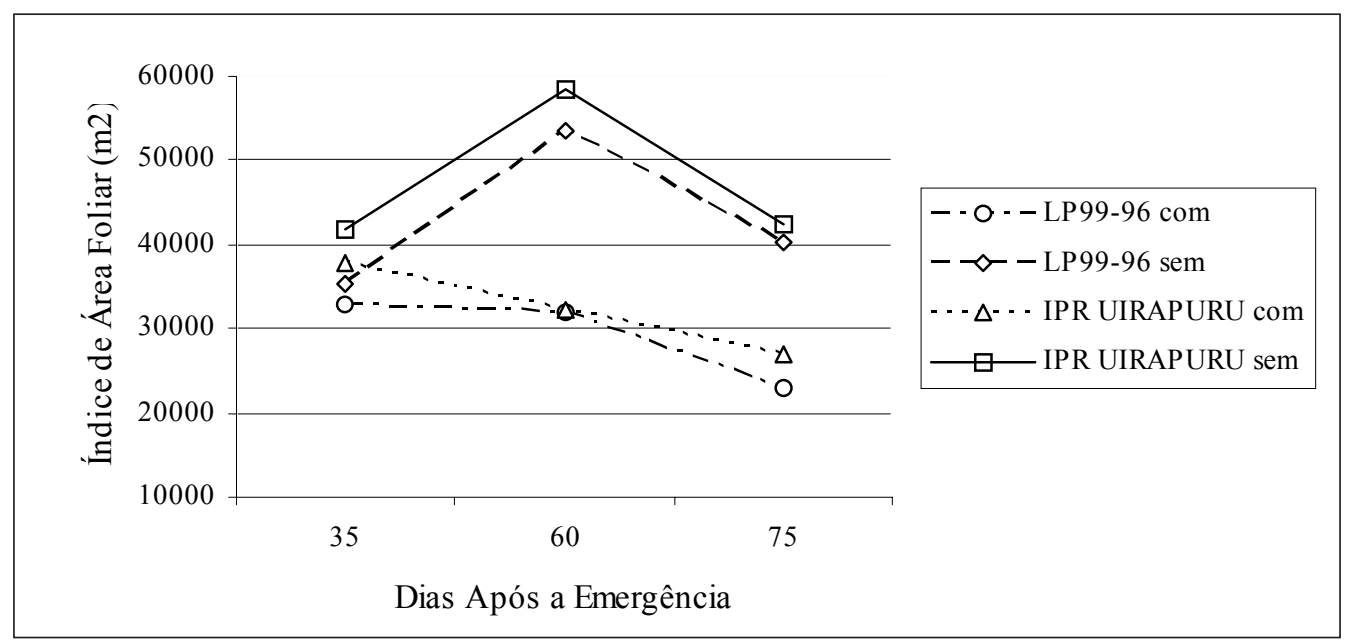

Figura 5. Índice de área foliar em $\mathrm{m}^{2}$, de dois genótipos de feijoeiro pertencentes ao grupo preto, com e sem estresse hídrico. Londrina-PR, safra das águas 2002/2003. 


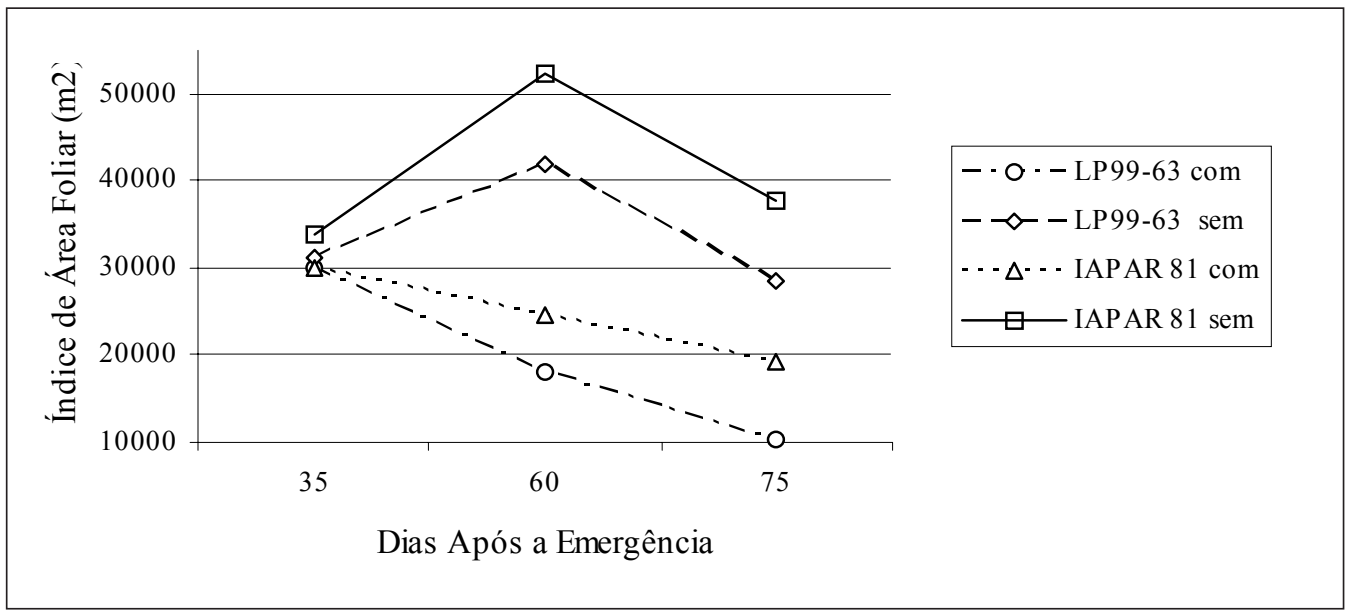

Figura 6. Índice de área foliar em $\mathrm{m}^{2}$, de dois genótipos de feijoeiro pertencentes ao grupo carioca, com e sem estresse hídrico. Londrina-PR, safra das águas 2002/2003.

As Figuras 7 e 8 ilustram a produtividade total de grãos dos tratamentos sem estresse $(\mathrm{kg} / \mathrm{ha})$ e os índices de redução (\%), para os grupos preto e carioca respectivamente. São considerados genótipos promissores os que apresentam alto potencial de rendimento de grãos e menores índices de redução de rendimento em condições com estresse. De acordo com este critério destacaram-se as linhagens LP 99-
85 e LP 99-79 para os grupos preto e carioca respectivamente. Deve-se ressaltar que em reunião do programa feijão no IAPAR, essas duas linhagens foram indicadas para cultivo no estado do Paraná, sendo que o registro da linhagem LP99-79 está sendo providenciado no Serviço Nacional de Registro de Cultivares-SNRC/MAPA, com a denominação de IPR Siriri.

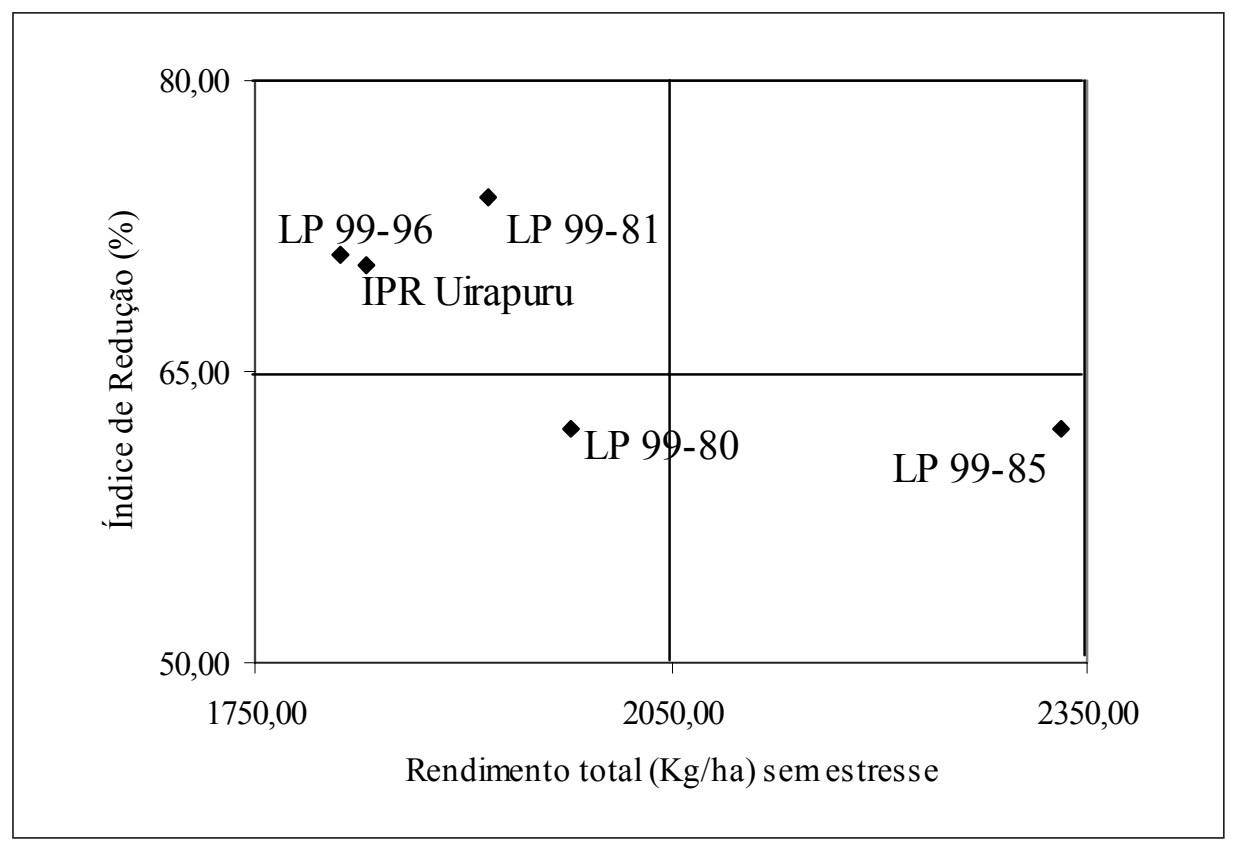

Figura 7. Relação entre rendimento (kg/ha) em condições sem estresse e índice de redução de rendimento (\%) de cinco genótipos de feijoeiro pertencentes ao grupo preto. Londrina-PR, safra das águas 2002/2003. 


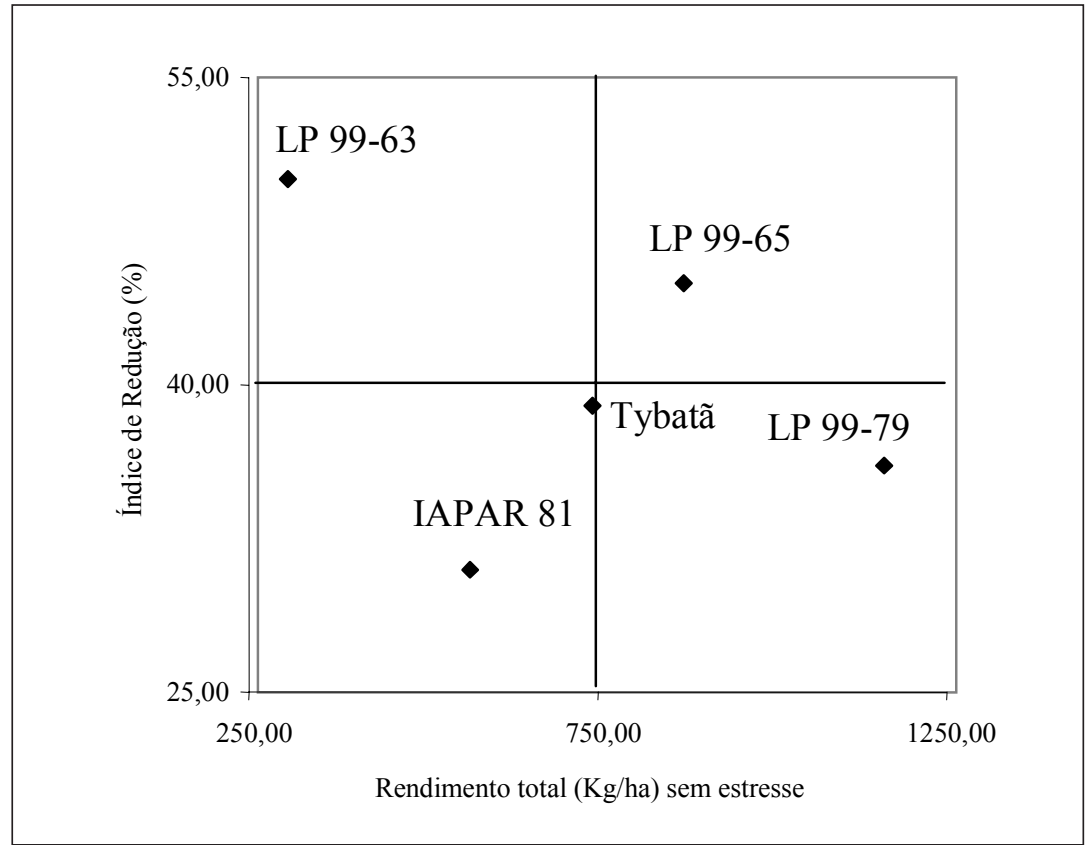

Figura 8. Relação entre rendimento $(\mathrm{Kg} / \mathrm{ha})$ em condições sem estresse e índice de redução de rendimento (\%) de cinco genótipos de feijoeiro pertencentes ao grupo carioca. Londrina-PR, safra das águas 2002/2003.

\section{Conclusões}

A metodologia aplicada foi eficaz para avaliar a reação ao déficit hídrico dos dez genótipos de feijoeiro avaliados, compreendendo os grupos comerciais preto e carioca.

Todas as características, com exceção do peso médio de 100 sementes, mostraram-se sensíveis à deficiência hídrica. Verificou-se substancial redução no rendimento total, tanto para o grupo comercial preto quanto para o carioca. Em todas os genótipos estudados, tanto o índice de área foliar como as taxas de matéria secas também diminuíram em condições de estresse hídrico.

As estimativas dos coeficientes de variação genética, dos coeficientes de variação ambiental e índices B indicaram a presença de variabilidade genética entre os genótipos estudados, para todas as características. As características que apresentaram maior variabilidade dentro do grupo comercial carioca foram altura de planta, peso médio de 100 sementes e rendimento total de grãos, enquanto que para o grupo comercial preto foi peso médio de 100 sementes e rendimento total de grãos.
As estimativas dos coeficientes de correlação fenotípica revelaram a presença de caracteres correlacionados indicando a possibilidade de se efetuar a seleção simultânea entre eles.

Considerando-se que a seca é o segundo maior redutor da produtividade do feijoeiro e que em algumas épocas de cultivo em determinadas regiões do Estado do Paraná a ocorrência de veranico é freqüente, a cultivar IAPAR 81 e a linhagem LP 9979 do grupo comercial carioca e a linhagem LP 9985 do grupo preto, que comportaram-se como tolerantes no presente estudo, constitui uma alternativa eficiente e econômica para garantir a estabilidade de produção em situações de estresse hídrico, contribuindo de maneira significativa para o desenvolvimento da agricultura nacional.

\section{Referências}

ACOSTA-GALLEGOS, J. A. Selection of common bean (Phaseolus vulgaris L.) genotypes with enhanced drought tolerance and biological nitrogen fixation. 1988. Thesis. (Ph.D) - Michigan State University, Michigan. 
ACOSTA-GALLEGOS, J. A.; ADAMS, M. W. Plant traits and yield stability of dry bean (Phaseolus vulgaris L. ) cultivars under drought stress. Journal of Agricultural Science, Cambridge, v. 116, n. 2, p. 213 -219, 1991.

BLUM, A. Crop responses to drought and the interpretation of adaptation. In: BELHASSEN, E. Drought tolerance in higher plants: genetical, physiological and molecular biology analysis. Dordrecht: Kluwer Academic, 1997. p. 57-70.

COMPANHIA NACIONAL DE ABASTECIMENTO CONAB. Produção Agropecuária. Disponível em: $<$ http/ /www.conab.gov.br/politica_agricola/safra/avalia.html $>$. Acesso em: 05 jun. 2007.

CRUZ, C. D. Programa GENES: aplicativo computacional em genética e estatística. Viçosa: UFV, 1997.

DUBETZ, S.; MAHLLE, P. S. Effect of soil water stress on bush beans (Phaseolus vulgaris L.), at three stages of growth. Journal of American Society for horticultural science, Alexandria, v. 94, n. 5, p. 479-481, 1969.

FARIA, R. T.; MADRAMOOTOO, C. A. Simulation of soil moisture profiles for wheat in Brazil. Agricultural Water Management, Amsterdam, v. 31, n. 1, p.35-49, 1996.

GARRIDO, M. A. T.; PURCINO, J. R. C. ; LIMA, C. A. S. Efeito do déficit de água em alguns períodos do ciclo de crescimento sobre o rendimento do feijoeiro comum In: EMPRESA DE PESQUISA AGROPECUÁRIA DE MINAS GERAIS - EPAMIG. Pesquisa feijão. Belo Horizonte: EPAMIG, 1979.p.77-78.

KARAMANOS, A. J.; PAPATHEOHARI, A. Y. Assessment of drought resistance of crop genotypes by means of the water potencial index. Crop Science, Madison, v. 39, n. 6, p. 1792-1797, 1999.

MAGALHÃES, A. A.; MILLAR, A. A. Efeito do déficit de água no período reprodutivo sobre a produção de feijão. Pesquisa Agropecuária Brasileira, Rio de Janeiro, v. 13, n. 2, p. 55-60, 1978.

MODA-CIRINO, V.; OLIARI, L.; FONSECA JÚNIOR, N. S.; LOLLATO, M. A. IAPAR 81 - Common bean. Crop Breeding and Applied Biotechnology, Londrina, v. 1, n. 2, p.203-204, 2001a.

. IPR Uirapuru - Common bean. Crop Breeding and Applied Biotechnology, Londrina, v. 1, n. 2, p. 205206, $2001 \mathrm{~b}$.

MOLINA, J. C.; MODA-CIRINO, V.; FONSECA JÚNIOR, N. S.; FARIA, R. T.; DESTRO, D. Response of common bean cultivars and lines to water stress. Crop Breeding and Apllied Biotechnology, Londrina, v. 1, n. 4, p. 363$372,2001$.
NIELSEN, C. D.; NELSON, N. O. Black bean sensivity to water stress at various growth stages. Crop Science, Madison, v. 38, n. 2, p. 422-427, 1998.

OLIVEIRA, D.; FARIA, R.T. Produção de feijoeiro submetido à submissão hídrica em diferentes fases do ciclo. In: REUNIÃO NACIONAL DE PESQUISA DE FEIJÃO, 5., 1996, Goiânia. Anais... Goiânia: EmbrapaCNPAF, 1996. p. 429-430.

PARJER, L. Invertigation of drought resistece in beans at different growth stages. Field Crops Abstracts, Wallingford, v. 11, n. 29, p. 776, 1976.

PIMENTEL, C.; LAFFRAY, D., LOUGUET, P. Intrinsic water use efficiency at the pollination stage as a parameter for drought tolerance selection in Phaseolus vulgaris. Physiologia Plantarum, Copenhagen, v. 106, n. 2, p. 184189, 1999.

RAGGI, L. A.; BERNARDO, S.; GALVÃO, D . G. Efeito do turno de rega em três fases do ciclo do feijoeiro. Seiva, Viçosa, v. 32, n. 76, p.34-43, 1972.

RAMIREZ-VALLEJO, P; KELLY, J. D. Traits related to drought resistance in common bean. Euphytica, Wageningen, v. 99, n. 2, p. 127-126, 1998.

SCHNEIDER, K. A.; BROTHERS, M.E.; KELLY, J.D. Marker assisted seletion to improve drought resistence in common bean. Crop Science, Madison, v. 37, n. 1, p. 51-60, 1997.

SILVEIRA, P. M.; GUIMARAES, C. M.; STONE, L. F.; KLUTHCOUSKI, J. Avaliação de cultivares de feijão para resistência à seca, baseada em dias de estresse de água no solo. Pesquisa Agropecuária Brasileira, Rio de Janeiro, v. 16, n. 5, p. 693-699, 1981.

SINGH, S. P. Selection for water-stress tolerance in interracial populations of common bean. Crop Science, Madison, v. 35, n. 1, p. 118-124, 1995.

STELL, R. G. D.; TORRIE, J. H. Principles of procedures estatistics. New York: Mc Graw Hill Book, 1960.

WHITE, J. W.; OCHOA, M.; IBARRA, P. F.; SINGH, S. P. Inheritance of seed yield, maturity and seed weight of common bean (Phaseolus vulgaris L.) under semi-arid rainfed conditions. Journal of Agriculture Science, Cambridge, v. 122, n. 2, p. 265-273, 1994.

WHITE, J. W. Implications ofcarbon isotope discrimination studies for breeding common bean under water deficits. In: EHLRINGER, J. R.; HALL, A. E.; FARQUHAR, G. D.; SAUGIE, B. (Ed.). Stable isotopes and plant carbon-water relations. San Diego: Academic Press, 1993. p. 387-398. 
